\title{
LOS ACUERDOS INTERNACIONALES SOBRE INVERSIÓN, OTRO OBSTÁCULO PARA EL DESARROLLO DE AMÉRICA LATINA ${ }^{1}$
}

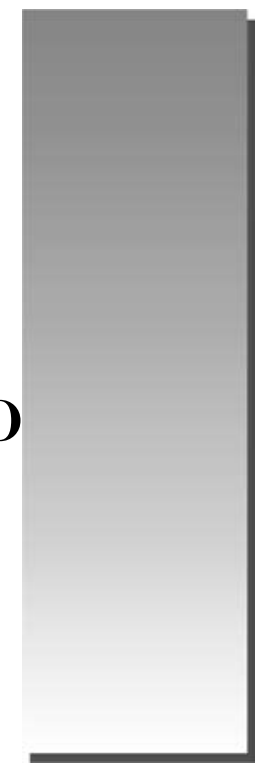

Patxi Zabalo (*)

E-mail: patxi.zabalo@ehu.es

\begin{abstract}
RESUMEN
Los acuerdos internacionales sobre inversiones, tanto los bilaterales como los insertos en tratados de integración económica, suponen la casi total apertura a la inversión extranjera y su protección una vez establecida en el país. Para las disputas prevén un sistema extraterritorial de solución de diferencias en el que las empresas pueden demandar directamente a los estados. La multiplicación de este tipo de demandas ante instancias de arbitraje internacional está desembocando en indemnizaciones multimillonarias y limitaciones intolerables de la soberanía nacional para establecer políticas públicas. Estos acuerdos han proliferado en América Latina durante las últimas dos décadas, y la experiencia acumulada no deja lugar a dudas sobre la gravedad del asunto. Por eso urge aplicar la doctrina Calvo, en virtud de la cual los posibles conflictos deben resolverse en los tribunales locales, quedando vedado el recurso al arbitraje internacional. Así, recuperando su plena soberanía jurisdiccional, los estados latinoamericanos estarán en mejores condiciones de llevar a cabo políticas de desarrollo.
\end{abstract}

Palabras clave: América Latina, Acuerdos Internacionales sobre Inversiones, Demandas InversorEstado, Soberanía Económica.

\begin{abstract}
The international agreements on investments, so much the bilateral as the insertions in tried economic integration, suppose the almost total opening to the foreign investment and its protection, once established in the country. For the differences prevents an exterritorial system of solution of differences in which the businesses can demand directly to the states. The multiplication of this type of demands in instances of international arbitration is flowing into in compensations multimillionaires and intolerable limitations of the national sovereignty to establish public politics. These agreements have proliferated in Latin America during the last two decades and the accumulated experience does not leave place to doubts on its gravity. Therefore it presses to apply the Calvo doctrine, in which
\end{abstract}

(*) Economista. Profesor de la Universidad del País Vasco/Euskal Herriko Unibertsitatea y miembro de Hegoa, Instituto de Estudios sobre Desarrollo y cooperación internacional.

1 Una versión preliminar de este trabajo se presentó como ponencia en XI Encuentro Internacional de Economistas sobre la Globalización y Problemas del Desarrollo, celebrado en La Habana (Cuba), del 02 al 06 de marzo del 2009. 
the possible conflicts should be resolved in the local courts, remaining preserve the resource to the international arbitration. Thus, recovering their full jurisdictional sovereignty, the Latin-American states will be in better conditions to carry out political of development.

Key words: Latin America, International Agreements on Investments, Investor-State Demands, Economic Sovereignty.

Los intentos de establecer unas reglas comunes para la inversión extranjera en el marco de una organización internacional han fracasado hasta el momento. Así ocurrió con el Acuerdo Multilateral sobre Inversiones (AMI) y tampoco han prosperado los intentos de introducir en la Organización Mundial de Comercio (OMC) un acuerdo sobre inversiones. Eso explica la proliferación desde los años 90 de una nueva generación de Acuerdos Internacionales sobre Inversiones (AII), uno de cuyos rasgos distintivos es la inclusión de un sistema de arreglo de diferencias que permite las demandas inversor-estado. Para los gobiernos del norte económico es otra vía para crear el anhelado clima favorable para el inversor externo, ya que extiende a ámbitos restringidos pero crecientes la libre circulación de capitales y su protección. Y para los gobiernos del sur y del este es parte de una estrategia de inserción en la globalización, compitiendo con otros receptores de inversión extranjera por un trozo del pastel ${ }^{2}$.

\section{LOS ACUERDOS INTERNACIONALES SOBRE INVERSIONES}

Hay dos tipos fundamentales de AII: los Tratados Bilaterales sobre Inversiones (TBI) y los Acuerdos de Integración Económica que también tratan sobre Inversiones (AIEI). Y en ambos casos su número ha crecido de manera espectacular durante los últimos quince años ${ }^{3}$. En efecto, de los 2,608 TBI suscritos al finalizar 2007, 2,223 son posteriores a 1990. A los TBI hay que sumar 254 AIEI, acuerdos de integración económica de alcance bilateral o regional, que incluyen disposiciones sobre inversiones ${ }^{4}$.
Al respecto, el Tratado de Libre Comercio de América del Norte (TLCAN), en vigor desde 1994 para Estados Unidos, Canadá y México, constituye la principal referencia, particularmente en lo relativo a las demandas inversor-estado. De hecho, el contenido del capítulo 11 del TLCAN, que trata sobre inversiones, es similar al de la mayoría de los TBI suscritos desde principios de los noventa, y es el modelo utilizado por Estados Unidos en los sucesivos borradores del Acuerdo de Libre Comercio de las Américas (ALCA), y en los Tratados de Libre Comercio (TLC) que va firmando con diversos países latinoamericanos ${ }^{5}$.

Dada la tupida y compleja red de AII, el alcance de sus disposiciones es muy difícil de determinar, y con su puesta en práctica cada vez se detectan más cuestiones problemáticas, ya que la interpretaciones expansivas de muchos paneles de arbitraje internacional amplían la ya de por sí acentuada asimetría entre los derechos reconocidos al inversor y las obligaciones impuestas a los estados.

La primera cuestión es muy básica: ¿qué o a quién se protege?, ya que resulta decisiva puesto que la respuesta delimita quién puede interponer una demanda. En la mayoría de los AII de nueva generación se opta por una definición muy amplia, considerando inversión a casi cualquier clase de activo, incluso una mera oficina de ventas, ya que de lo que se trata es de liberalizar todo tipo de movimientos de capital y proteger los intereses del inversor. $Y$ es que los destinatarios finales de la protección no son las inversiones sino los inversores $^{6}$; por ello, tanto un accionista mayoritario como uno minoritario quedan amparados por

2 Ver Elkins y otros. (2007).

3 Además de las dos categorías de acuerdos que aquí se tienen en cuenta, la UNCTAD incluye entre los AIIs los tratados sobre doble imposición (TDI). Dado que hay más de 2,730 TDI, la cifra total de AII se sitúa entonces muy cerca de los 5,600. Al margen de otras consideraciones sobre su menor alcance respecto a otros acuerdos relativos a inversiones, estén o no inscritos en uno más amplio, el motivo de su exclusión es que los TDI no resultan relevantes para el objeto de este trabajo, centrado en las disputas inversor-estado.

4 Ver UNCTAD (2008c).

5 Ver Gal-Or. (2005). Pág. 123.

6 Ver Granato (2005). Págs. 15-17. 
estos acuerdos para hacer valer sus derechos de inversor extranjero ${ }^{7}$.

Una segunda cuestión es determinar en qué términos se protegen los derechos del inversor externo. Se trata de delimitar el alcance de la aplicación de las cláusulas de trato nacional, de nación más favorecida, de trato justo y equitativo, y también de la llamada cláusula general (o umbrella clause). Las dos primeras hacen referencia al principio de no discriminación y tienen larga tradición en los acuerdos comerciales, pero su interpretación extensiva por los paneles de arbitraje plantea problemas. Así, la cláusula de "nación más favorecida" (NMF) se utiliza para proporcionar acceso a previsiones más favorables contempladas en otros AlI ${ }^{8}$. Por su parte, la cláusula que garantiza al inversor un "trato justo y equitativo" ha resultado ser una de las disposiciones más poderosas para la protección del inversor extranjero, ya que por su generalidad puede abarcar casi cualquier eventualidad, relegando a otras previsiones a meros caso particulares ${ }^{9}$. Así diversos laudos subrayan la obligación del estado receptor de mantener un escenario legal para los negocios estable y predecible, y que sea compatible con las legítimas expectativas del inversor ${ }^{10}$. También la "cláusula general", que garantiza el respeto a toda obligación asumida por un estado respecto a inversiones, ha sido objeto de interpretaciones expansivas que permiten extender a las obligaciones contractuales la protección proporcionada por los $\mathrm{TBI}^{11}$.

Una tercera cuestión concierne a la llamada expropiación indirecta. A diferencia de la verdadera expropiación o nacionalización, no supone una transferencia de la propiedad, sino la mera desvalorización de un activo debido a una intervención estatal ${ }^{12}$. Se trata de una construcción jurídica relativamente reciente, impulsada por grupos empresariales que pretenden conseguir indemnizaciones de las autoridades públicas cuando éstas dicten normas referidas a la protección ambiental, el uso de la tierra u otros asuntos de interés público que, a su juicio, afectan negativamente al valor de su propiedad. Al respecto, es importante señalar que los intentos de hacerla valer en Estados Unidos han sido reiteradamente rechazados durante las dos últimas décadas por los juzgados de ese país, incluido su Tribunal Supremo ${ }^{13}$. No obstante, muchos AII recientes incluyen la "expropiación indirecta" y "medidas de efecto equivalente", aunque no definen esos términos ${ }^{14}$, mientras que los paneles de arbitraje internacional vienen haciendo dos lecturas completamente divergentes de este asunto. Unos sostienen que el elemento clave para determinar si ha habido expropiación indirecta es el impacto económico de la medida, con independencia de su motivación, mientras otros mantienen que genuinas medidas regulatorias no son expropiaciones $^{15}$.

Junto a estas tres cuestiones subsisten otras inquietudes respecto a asuntos como la transferencia de fondos, las reglas de la competencia, la prohibición de los requisitos de desempeño, o los derechos de la propiedad intelectual ${ }^{16}$. Pero sobre todo son las demandas inversor-estado y los oscuros procedimientos que las resuelven el principal motivo de preocupación, ya que pueden resultar fatales para el desarrollo de multitud de economías del sur.

\section{LAS DEMANDAS INVERSOR-ESTADO Y SUS COSTES}

Las demandas inversor-estado se solventan en instancias de arbitraje internacional, a las que remiten los acuerdos sobre inversiones. Ahora bien, la única institución de arbitraje internacional

7 Incluso se puede practicar el forum shopping, que consiste en que el inversor elige el TBI que más le conviene con independencia de su verdadero país de origen. Para ello basta con crear una sociedad instrumental en el país cuyo tratado contenga las disposiciones más favorables y trasladar allí la sede social. Ver Sacerdoti (2007). Págs. 9-10.

8 Por ejemplo un panel del CIADI, al resolver la demanda de un inversor malayo contra Chile, importó las formulaciones más favorables para el demandante recogidas en los TBI suscritos por Chile con Dinamarca y Croacia. Ver Public Citizen (2005). Pág. 93.

9 Ver Lowe (2007). Págs. 77-83.

10 Ver UNCTAD (2008b). Págs. 4-5.

11 Ver Lowe (2007). Págs. 102-106.

12 Op. Cit. Págs. 53-76.

13 Ver Public Citizen. (2005). Pág. 14.

14 Ver UNCTAD. (2004). Págs. 67-71.

15 Ver Malik. (2008).

16 Ver UNCTAD. (2006). Pág. 38-46. 
expresamente creada para dirimir disputas entre inversores extranjeros y estados es el Centro Internacional para el Arreglo de Diferencias relativas a Inversiones (CIADI), creado en 1965 en el marco del Grupo del Banco Mundial, que es al que remiten más All y también es el más utilizado. Otras instancias mencionadas en algunos AIl son el Instituto de Arbitraje de la Cámara de Comercio de Estocolmo (CCE) y la Corte de Arbitraje de la Cámara de Comercio Internacional (CCI). Cada una de ellas se rige por sus propias reglas, que no estaban inicialmente establecidas para resolver diferencias inversor-estado sino para disputas comerciales entre empresas. Lo mismo ocurre con las reglas establecidas en 1976 por la Comisión de Naciones Unidas para el Derecho Mercantil Internacional (CNUDMI), que se utilizan en procedimientos de arbitraje ad hoc celebrados en cualquier lugar acordado entre la partes, ya que la CNUDMI simplemente proporciona unas reglas que otros administran ${ }^{17}$.

Así, mientras las leyes de cualquier país democrático son aprobadas por su parlamento, las reglas de arbitraje no son el resultado de algún procedimiento legislativo; más bien provienen de una estrategia impulsada desde hace décadas por asociaciones empresariales y de abogados para privatizar la justicia, al menos en lo relativo al derecho mercantil. Rompiendo con siglos de tradición jurídica, se establece una vía alternativa para resolver disputas comerciales en la que se sacrifican garantías en aras de la rapidez y eficacia. Por eso una de sus peculiaridades es que no hay posibilidad de apelación ante un órgano superior $^{18}$, lo que adquiere mayor trascendencia cuando una de las partes implicadas es un estado, ya que supone una evidente merma de su soberanía.

Otra peculiaridad es que, a diferencia de los tribunales de justicia, los tribunales de arbitraje, normalmente llamados paneles, son designados para cada ocasión. En la práctica la mayoría de los árbitros proceden de importantes despachos de abogados especializados en arbitraje internacional ${ }^{19}$. Por eso es habitual que la misma persona actúe unas veces como asesor de empresas multinacionales y otras como árbitro en litigios semejantes. Eso les facilita impulsar interpretaciones extensivas de los AII, favorables a los intereses de las multinacionales. Y es que el arbitraje internacional no deja de ser un sistema concebido para proporcionar "justicia privada al servicio de los comerciantes" $"$.

Una de las características de los procesos de arbitraje internacional inversor-estado es su falta de transparencia. De hecho, únicamente el CIADI proporciona algo tan básico como un registro público de demandas interpuestas junto a una muy limitada información sobre su contenido. En las demás instancias arbitrales la propia existencia de una demanda y su resolución sólo es conocida si una de las partes implicadas la hace pública, ya que las audiencias ante los tribunales arbitrales no son públicas y el laudo sólo se notifica a las partes $^{21}$.

La proliferación de acuerdos internacionales sobre inversión de nueva generación se ha traducido en un incremento espectacular de las demandas inversor-estado. Hasta 1995 se habían interpuesto seis demandas -la primera de ellas en 1987- y desde entonces hasta el fin del 2007 se han presentado otras 284 , cerca del $80 \%$ de ellas desde el 2002. Estas cifras son las únicas disponibles pero infravaloran la realidad, ya que hacen referencia a los casos conocidos ${ }^{22}$.

En torno al 90\% de las demandas conocidas, éstas han sido interpuestas por la casa matriz de una empresa multinacional con sede en un país del norte ${ }^{23}$. Y respecto al resultado, hasta fines del 2007, los laudos arbitrales favorables al inversor demandante han sido 40 , los casos que no han sido perdidos ${ }^{24}$ por el estado demandado ascienden a 42 , y hay 17 decisiones arbitrales de las que

17 Ver Cosbey y otros. (2004). Pág. 4-5.

18 Ver Sondow (2006).

19 Tres cuartas partes de los árbitros proceden de países de la OCDE, encabezados por los estadounidenses (18\%) y británicos $(10 \%)$, y sólo el 3.5\% son mujeres. Ver Franck. (2007b). Págs. 77-83.

20 Ver Cosbey y otros. (2004). Págs. 4-7.

21 Ver UNCTAD. (2005b). Págs. 5-6; también Marshall. (2008).

22 Ver UNCTAD (2008b).

23 Ver UNCTAD. (2008a). Pág. 16; también Franck. (2007). Pág. 29.

24 Tal y como funciona el arbitraje internacional, los estados nunca pueden ganar, su mejor resultado es no perder. Además ni siquiera esto sale gratis dados los costes de la defensa que casi nunca se imputan al inversor por estrafalaria que sea su demanda. Ver Gobierno de Bolivia. (2008). Págs. 110 y 119. 
no se conoce el sentido; mientras que 37 casos han acabado con un acuerdo entre las partes, y 154 siguen pendientes de resolución ${ }^{25}$.

A finales del 2007 habían sido demandados por lo menos 73 estados. Pero los procedimientos arbitrales abiertos están bastante concentrados: los cinco primeros países suponen el $35 \%$ de las demandas. La lista la encabeza Argentina con 46 causas en su contra, seguida por México con 18 imputaciones, y en tercer lugar se sitúa la República Checa con 14. Después aparecen Estados Unidos y Canadá con 12 demandas cada uno ${ }^{26}$. Por regiones destaca América Latina, que acumula más de la tercera parte de las demandas (103), seguida por los países del este (ex bloque soviético), con 89 causas.

El coste económico directo de las disputas inversor-estado se compone de un gasto fijo (el coste del litigio) al que, en caso de que la demanda prospere, se suma la indemnización que ha de pagar al inversor externo. Aunque Susan Franck ${ }^{27}$ estima un promedio de US\$ 719,000 de coste para el estado demandado, otros estudios establecen un coste mínimo de US\$ 500,000 por caso, con un promedio situado entre US\$ 2 y US\$ 3 millones. Así, el gobierno de la República Checa informa que su defensa en los dos casos Lauder le costó más de US\$ 10 millones $^{28}$, mientras que el gobierno de Bolivia reconoce haberse gastado US\$ 1.6 millones para defenderse contra Aguas de Tunari/Bechtel. Además, si hay que pagar los gastos del demandante, los costes se duplican. Así, en 2006 Hungría, al perder su pleito frente a ADC, tuvo que pagar US\$ 7.6 millones $^{29}$.

Respecto a las indemnizaciones hasta ahora la mayor cantidad conocida con que ha sido condenado un estado son los US\$ 824 millones, más US\$ 10 millones de costas del proceso que tuvo que pagar Eslovaquia a CSOB en el $2004^{30}$. Pero reclamaciones más elevadas están pendientes de resolución. La mayor asciende a US\$33,000 millones, repartida entre tres demandas interpuestas en 2005 contra Rusia por accionistas de Yukos; seguida por US\$ 4,600 millones pedidos por Cementownia a Turquía en 2006, y los US\$1,116 millones de Emelec a Ecuador en 2005. Así, una cantidad tan respetable como US\$ 1,000 millones se ha convertido en habitual y la reclaman Eurotunnel a Francia y el Reino Unido en el 2003, Total a Argentina en el 2004 y Occidental a Ecuador en el 2006. Incluso en casos que han concluido por acuerdo entre las partes se conocen importantes cifras abonadas para lograr la retirada de la demanda. Así, se sabe que Motorola recibió US\$ 900 millones de Turquía en el 2004, o que en el 2003 la India pagó US\$ 160 millones a Bechtel y US\$ 145 a GE a cambio de que retiraran una reclamación conjunta de US\$ 600 millones $^{31}$.

Por su parte, el temor de un estado a enfrentarse a indemnizaciones millonarias debido a reclamaciones de "expropiación indirecta" o "regulación expropiatoria" puede dar lugar a lo que se ha llamado enfriamiento regulatorio ${ }^{32}$; es decir, una contención preventiva de las autoridades que se traduce en una menor o más débil actividad normativa en defensa del interés público, ya que la amenaza de una demanda inversor-estado es suficiente para que el gobierno enmiende, aplace, retire, o no haga cumplir determinada norma. En este sentido, los AII implican un coste político en forma de limitación de la soberanía nacional para dictar políticas públicas. Como en el arbitraje internacional no hay unificación de doctrina, y los laudos sobre "expropiación indirecta" son contradictorios, la incertidumbre sobre qué espacio tiene el estado para hacer política persiste ${ }^{33}$.

Además, la liberalización y protección brindada por los AII no se limita a la inversión extranjera directa (IED), sino que abarca a todo tipo de inversor de carácter especulativo, cuya responsabilidad en las crisis financieras es bien conocida. Y no se les otorga un tratamiento igual al inversor nacional sino mejor, dándose la paradoja de que un régimen basado en la no discriminación (trato nacional y NMF) resulta ser esencialmente

25 Ver UNCTAD. (2008b).

26 Op. cit.

27 Franck. (2007). Pág. 66-70.

28 Ver UNCTAD. (2005). Pág. 10.

29 Ver UNCTAD. (2008).

30 Ver UNCTAD. (2005). Pág. 9.

31 Ver UNCTAD, Base de datos.

32 Ver UNCTAD. (2005). Pág. 48; también Moltke y Mann. (2004). Pág. 29-30.

33 Ver Yu y Marshall. (2008). Pág. 23. 
discriminatorio. En efecto, para las empresas locales sólo existe la vía de los tribunales nacionales regidos por su ordenamiento jurídico. En cambio, para el invasor extranjero cabe la posibilidad de recurrir al arbitraje internacional, e invocar un trato justo y equitativo o la existencia de una expropiación indirecta, independientemente de que eso sea posible o no, bajo las leyes del estado receptor ${ }^{34}$. Por eso, como sostiene Public Citizen ${ }^{35}$, lo que se planteaba como un escudo protector contra los posibles abusos de los estados receptores de inversiones ha resultado ser una espada empuñada por multitud de inversores extranjeros contra los estados firmantes de AII.

Invocando la seguridad jurídica se pretende agilizar la justicia privatizándola de hecho. En realidad, eso significa reducción de garantías ya que no hay jueces propiamente dichos ni vista oral, ni apelación, ni jurisprudencia, ni acumulación de causas similares, pero sí un procedimiento arbitral que permite muchas menos pruebas que las jurisdicción ordinaria, y paneles que deciden sobre su propia competencia y jurisdicción ${ }^{36}$. De este modo, se han logrado hitos como dos laudos contrarios y sin posible casación para un mismo caso $^{37}$.

\section{AMÉRICA LATINA COMIENZA EL SIGLO XXI CON UNA AVALANCHA DE DEMANDAS INVERSOR- ESTADO}

Aunque América Latina destaca por la cantidad de demandas inversor-estado de que ha sido objeto, la firma de TBI y otros AIl que las permiten no se generalizó en la región hasta los años 90. De hecho, durante la primera mitad de los años 60, los países latinoamericanos, con base en la doctrina Calvo, rechazaron colectivamente el sistema de arbitraje internacional inversor-estado del $\mathrm{CIADI}^{38}$. Sin embargo, actualmente 14 estados latinoamericanos forman parte del CIADI, tras el abandono de la institución por Bolivia en el 2007 y Ecuador en el $2009^{39}$. La mayoría ingresaron en la década pasada, pero las dos mayores economías de la región, Brasil y México, no participan en el CIADI. Ahora bien, mientras México ha aceptado un mecanismo similar en el marco del TLCAN y desde finales de los noventa ha firmado $23 \mathrm{TBI}$, Brasil no está afectado por ningún AII, a pesar de haber firmado $14 \mathrm{TBI}$ durante la segunda mitad de los años 90 ya que no los ha ratificado ${ }^{40}$.

Esa cadencia en la firma de All contribuye a explicar que hasta el año 2000 los gobiernos de América Latina sólo se hubieran enfrentado a 12 demandas inversor-estado, la primera de ellas en 1995. En cambio, entre 2001 y 2007 han recibido por lo menos 91 , lo que supone un promedio de 13 al año, y la mitad de esas 91 han sido contra Argentina que antes del 2001 sólo había sido demandada una vez en $1997^{41}$. En total, hasta finalizar 2007, a las 46 demandas contra Argentina le siguen de lejos las 18 de México, nueve de Ecuador, siete de Venezuela, cinco de Chile y tres de Bolivia ${ }^{42}$.

Los datos que se van conociendo sobre los años 2008 y 2009 apuntan en la misma dirección. En octubre del 2009, sólo ante el CIADI, hay cuatro nuevas demandas contra Ecuador que consolida su tercera posición entre los países latinoamericanos; tres contra Argentina y Venezuela; dos contra Costa Rica y El Salvador; y una contra Guatemala y Honduras ${ }^{43}$. Y al menos hay otra demanda contra Bolivia ante la Cámara de Comercio de Estocol-

34 Ver Lowe. (2007). Págs. 48-49.

35 Ver Public Citizen. (2005). Pág. 86.

36 Ver Sondow. (2006). Pág. 1.

37 En efecto, fruto de dos demandas diferentes (casos Lauder) que fueron admitidas por sus respectivos paneles bajo las reglas del CNUDMI por referirse a distintos TBI, un demandante perdió el caso pero al otro le concedieron una indemnización de más de US\$ 300 millones a cargo del erario checo. Ver UNCTAD. (2005b). Pág. 17; Franck. (2005). Págs. 1559-1568, y Sacerdote. (2007). Y aunque esto pasó en el 2001, no hay nada posterior que evite su repetición, salvo en el ámbito del TLCAN y los AIl suscritos por Estados Unidos desde el 2004, que prevén un procedimiento que permite reunir en un solo panel demandas relacionadas. Ver Cosbey y otros. (2004). Pág. 33.

38 Ver Teitelbaum. (2004). Pág. 10.

39 Ecuador comunicó oficialmente al CIADI su abandono de la institución el 06 de julio del 2009. De acuerdo con sus reglas, será efectiva seis meses después, es decir el 07 de enero del 2010.

40 Ver UNCTAD, Base de datos.

41 Op. Cit.

42 Ver UNCTAD. (2008b). Pág. 14.

43 Ver CIADI, List of Cases.

44 Ver UNCTAD, Base de datos. 
$\mathrm{mo}^{44}$. Por eso, dejando para más adelante el caso de Argentina, se abordan algunos inquietantes hechos recientes.

No resulta alentador que, al poco de entrar en vigor, ya se esté utilizando el capítulo sobre inversiones del TLCCA-RD para presentar demandas inversor-estado contra los países de esa área. Al respecto, hay que recordar que el TLCAN dio lugar a un rápido crecimiento de demandas inversor-estado, tanto a su amparo como al de diversos $\mathrm{TBI}^{45}$.

La multiplicación de casos contra Ecuador es otra muestra del riesgo que para los estados receptores entraña suscribir AII, sobre todo si alguna vez pretenden realizar una política económica progresista. De hecho, la mayoría de las demandas provienen del sector petrolero y son posteriores a la ley que en el 2006 estableció un reparto al $50 \%$ de los ingresos extraordinarios obtenidos por las compañías debido al alto precio del petróleo, ampliada por decreto en el 2007. Aunque no prosperen o se resuelvan por un acuerdo entre la partes, la mera presentación de esas demandas supone una intromisión en la voluntad soberana de Ecuador para regular la explotación de sus recursos naturales. Prueba de ello es la reciente y turbulenta renegociación del contrato de Repsol-YPF con el gobierno ecuatoriano, en la que ha mediado una demanda ante el CIADI en junio del 2008 para llegar a un acuerdo cinco meses después ${ }^{45}$. Y es que, a pesar de haber obtenido recientemente algunos laudos favorables, sobre Ecuador pende la amenaza de varias demandas multimillonarias por un monto estimado de US\$ 10,000 millones ${ }^{46}$, con el antecedente de haber sido ya condenado en el 2004 a pagar más de US\$ 75 millones a Occidental, una de las últimas demandantes, que ahora solicita entre US\$ 1,000 y US\$ 3,000 millones de indemnización, según las fuentes ${ }^{47}$.

En ese contexto, Ecuador notificó al CIADI en octubre del 2007 que no admitiría demandas sobre recursos no renovables. Posteriormente el gobierno ecuatoriano ha anunciado que va a denunciar nueve de sus $24 \mathrm{TBI}$ en vigor (con ocho países latinoamericanos y con Rumania), dado que no aportan ningún beneficio a la economía del país, y en julio del 2009 ha abandonado el CIADI. En conjunto esas decisiones son un avance importante para evitar la proliferación de demandas, pero su eficacia a corto plazo no es evidente. Tanto la notificación del 2007 como el más contundente abandono del CIADI no son por sí mismos suficientes para revocar plenamente el consentimiento dado en los TBI suscritos, que normalmente incluyen otras instancias alternativas para el arbitraje. Por su parte, la denuncia de los tratados no impide que estos mantengan su vigencia durante un largo periodo posterior, que suele ser de diez años, y además los TBI no denunciados incluyen a los principales países de origen de las multinacionales ${ }^{48}$.

Por su parte, el caso de Bolivia deja bien claro lo difícil que resulta dar marcha atrás una vez que se ha entrado en la dinámica de suscribir AlI. Por un lado, a pesar de haberse retirado del CIADI el 02 de mayo del 2007, ha visto como este organismo registraba en octubre de ese año una demanda de ETI, empresa telefónica supuestamente radicada en Holanda, aunque en realidad es propiedad de Telecom Italia. El CIADI se basa en que la baja de Bolivia no es efectiva hasta seis meses después de comunicada ${ }^{49}$, pero el Gobierno de Bolivia ${ }^{50}$, al igual que ciertos juristas, alega que desde mayo ha retirado el imprescindible consentimiento de las partes para que una demanda sea aceptada a trámite (registrada), y considera esta actuación del CIADI una violación inadmisible de su derecho soberano a denunciar un tratado. Por otro lado, Bolivia ha sido demandada en el 2008 por una empresa con sede en Luxemburgo ante la CCE al existir esa posibilidad en el correspondiente TBI. Por eso no debe extrañar que desde el ALBA (Alternativa Bolivariana para las Américas) se esté impulsando un foro alternativo al CIADI ${ }^{51}$, o que el gobierno ecuatoriano promueva un Foro Latinoamericano de Arbitraje ${ }^{52}$.

45 Ver Intermpón. (2008). Pág. 19, y los diarios El País del 01 de noviembre del 2008 y ABC del 07 y 08 de noviembre del 2008 , ambos de Madrid.

46 Ver ITN, del 01 de septiembre del 2008.

47 Ver ITN, del 01 de octubre del 2008.

48 Ver ITN, del 05 de febrero del 2008.

49 Ver ITN, del 15 de noviembre del 2007.

50 Ver Gobierno de Bolivia. (2008). Págs. 124-127.

51 Ver ITN, del 01 de octubre del 2008

52 Ver Gutiérrez-Haces. (2007). Pág. 9. 


\section{EL CASO DE ARGENTINA}

A mediados de 2009 Argentina se enfrenta, al menos, a 49 demandas ante tribunales internacionales de arbitraje ${ }^{53}$, la mayoría de ellas ante el CIADI. Casi todas están relacionadas con las medidas que adoptó el gobierno para hacer frente a la crisis financiera que estalló a finales de 2001 entre las que destaca el abandono del tipo de cambio fijo entre el peso y el dólar estadounidense. En efecto, la Ley de Emergencia Económica, adoptada en el 2002 y prorrogada hasta la actualidad, es el blanco preferido de casi todas las demandas interpuestas tras la devaluación. Entre otras disposiciones, esta Ley № 25561 de Emergencia Pública y de Reforma del Régimen Cambiario incluye un capítulo dedicado a los contratos públicos que deja sin efecto las cláusulas de ajuste en dólares y las cláusulas de ajuste basadas en el índice de precios estadounidense y cualquier otro mecanismo indexatorio, pesifica las tarifas, y autoriza al gobierno a renegociar los contratos.

Una pieza fundamental de la estrategia legal del gobierno argentino ha consistido en invocar una cláusula que figura en varios de los TBI firmados por Argentina que limita la aplicabilidad de la protección del inversor en circunstancias excepcionales. Su efecto es similar al llamado "estado de necesidad" reconocido en la mayoría de las legislaciones nacionales. Este tipo de disposiciones permiten tomar medidas que en circunstancias normales irían contra el tratado cuando, por ejemplo, son necesarias para la protección de la seguridad nacional, el mantenimiento del orden público o para responder a una emergencia sanitaria. En tanto las actuaciones del estado receptor se tomen persiguiendo alguno de los objetivos especificados en esa cláusula, medidas que de otro modo estarían prohibidas por el tratado, no constituyen rupturas del mismo y el estado queda eximido de responsabilidad bajo el TBI. El gobierno de Argentina considera que la situación de emergencia económica abierta por la crisis desatada a finales de 2001 se ajusta perfectamente a esta cláusula, por lo que no se le pueden imputar ninguna responsabilidad por las medidas adoptadas para afrontarla ${ }^{54,55}$. Sin embargo, con diversas pero todas ellas muy restrictivas lecturas de los tratados, los paneles de arbitraje del CIADI han rechazado la sólida argumentación de Argentina, considerando que la situación no era de emergencia, salvo el panel del caso LG\&E que ha entendido que sí lo era durante 18 meses $^{56}$.

Muestra de la debilidad jurídica pero también del potencial perjudicial de esos paneles es el caso CMS. En efecto, el procedimiento de anulación del laudo condenatorio interpuesto por Argentina concluyó en septiembre del 2007 con una resolución del comité ad hoc de anulación del CIADI que ha causado estupor. Primero anula la parte del laudo que aplicaba la cláusula general y reconoce que hay otras secciones que contienen errores de razonamiento legal que podrían haber tenido un impacto decisivo en la parte operativa de la sentencia. Pero, acto seguido, declara carecer de poder para anular esas partes y mantiene la multa del laudo original ${ }^{57}$.

Y sobre la catadura de algunos demandantes sirva como ejemplo el caso de Siemens, que logró en 2007 una indemnización de US\$217.8 millones por la rescisión en el 2000 del contrato que había firmado en 1998 con el gobierno de Argentina para confeccionar los documentos nacionales de identidad ${ }^{58}$. Posteriormente se ha confirmado que Siemens consiguió el contrato pagando sobornos por valor de unos US\$ 70 millones a diversos miembros del gobierno argentino. De hecho, Siemens ha admitido ante la justicia alemana y estadounidense haber realizado múltiples sobornos, asumiendo pagar US\$ 1,360 millones en multas. Argentina, que ya había planteado el asunto de las coimas durante el arbitraje sin lograr que el panel admitiera pruebas al respecto, pidió que se revisase el laudo sin conseguirlo ${ }^{59}$. Pero la solución ha venido por otro lado: Siemens ha

53 A finales de agosto del 2009, TELECOM Italia ha anunciado que presentaría una demanda contra Argentina en instancias internacionales (ver el diario El Clarín, del 28 de agosto del 2009), por lo que serían, al menos, 50 causas.

54 Resulta interesante señalar que esta cláusula figura en todos los TBI firmados por Estados Unidos, país que la venía incluyendo desde hace décadas en sus acuerdos de Amistad, Comercio y Navegación, y que ya aparece en el primer TBI suscrito en 1959 por Alemania y Pakistán.

55 Ver Burke-White y Staden. (2008). Págs. 311-317.

56 Op. cit. Págs. 393-400.

57 Ver ITN, del 15 de octubre del 2007.

58 Ver UNCTAD. (2008b).

59 Ver Página12, del 20 de abril y 18 de diciembre del 2008; también ITN de enero del 2009. 
retirado la demanda en un intento de restablecer su imagen pública ${ }^{60}$.

De momento, Argentina ha sido condenada en nueve ocasiones, la primera en el 2005, y las indemnizaciones suman ya US\$ 1,150 millones, a los que hay que añadir los correspondientes intereses. Y aunque dada la falta de transparencia de los procesos de arbitraje las estimaciones varían según las fuentes, pero podemos decir que las cifras demandadas se sitúan entre los US\$16,000 y los US\$ 20,000 millones ${ }^{61}$.

Con todo, hasta mediados del 2009, el gobierno argentino no ha abonado ninguna de esas cantidades en cuatro casos por encontrarse los laudos pendientes de la resolución de un comité de anulación del $\mathrm{CIADI}^{62}$. Sin embargo, ese trámite ya concluyó sin éxito para Argentina en los casos de CMS, en septiembre del 2007, y Azurix y Sempra durante el verano del 2009. Y, a pesar de haberse dirigido al gobierno argentino solicitando el pago de la indemnización y contar con la presión del Departamento de Estado de Estado Unidos ${ }^{63}$, todavía están esperando a cobrar. La respuesta de la Procuración del Tesoro de Argentina es que, según su interpretación del Convenio del CIADI, el inversor externo debe pedir la ejecución del laudo del CIADI ante el tribunal competente, que en este caso es la Cámara de Apelaciones en lo Contencioso Administrativo Federal de Buenos Aires ${ }^{64}$.

De todas maneras, las maniobras dilatorias del gobierno argentino a la hora de pagar no evitan que las condenas se vayan acumulando a medida que van concluyendo los arbitrajes, y al coste de las indemnizaciones hay que sumar los procesales y de defensa ${ }^{65}$, y el de las renegociaciones que han permitido la retirada de diversas demandas. De hecho, se han retirado al menos diez demandas ante el CIADI ${ }^{66}$, varias de ellas tras realizar gestiones con los gobiernos español y francés, cuya compensación se encuentra en el contrato renegociado con el gobierno argentino ${ }^{67}$. Un caso peculiar es el de Sempra, accionista minoritaria de Camuzzi, ya que, según la Procuración del Tesoro argentino, la indemnización de US\$ 172 millones será derivada al accionista mayoritario porque así se convino en la renegociación del contrato con el gobierno ${ }^{68}$.

Otra cuestión inquietante son las razones expuestas en los laudos condenatorios contra Argentina, tanto por ser contradictorios entre sí y sin posible casación, como por el más que amplio contenido otorgado a la cláusula de trato justo y equitativo. Por un lado, el alegato de "estado de necesidad" planteado sistemáticamente por Argentina sólo ha sido parcialmente aceptado en el caso LG\&E, pero rechazado en los laudos de CMS, Enron y Sempra, todos ellos ante el CIADI, en el de British Gas ante la $\mathrm{CCl}^{69}$, y en el de National Grid bajo las reglas de la $\mathrm{CNUDMI}^{70}$. Y ello a pesar de que los casos son muy similares, y de que en los litigios de LG\&E y Enron han coincidido uno de los tres árbitros, sin que en ninguno de los laudos haya hecho constar una posición discrepante ${ }^{71} \mathrm{de}$ la mayoría ${ }^{72}$. Por otro lado, sólo en las demandas de Siemens y Vivendi ${ }^{73}$ se ha aceptado el alegato

60 Ver diario El Clarín, del 13 de agosto del 2009.

61 Ver Stanley. (2004). Pág. 38; y Mortimore y Stanley. (2006). Pág. 26.

62 Ver CIADI, List of Cases.

63 Ver ITN, de abril del 2009; también revisar diario El Clarín, del 31 de agosto del 2008 y del 09 de octubre del 2009

64 Ver diario El Clarín, del 04 de septiembre del 2008.

65 De hecho en el 2003 este país se vio obligado a crear un organismo encargado de su defensa ante las demandas inversorestado que es la Unidad de Asistencia para la Defensa Arbitral, presidida por el titular de la Procuración del Tesoro de la Nación, que es la asesoría jurídica de más alto rango del Presidente y representa al estado en ciertos litigios. Ver Granato. (2005). Pág. 106.

66 Ver ITN, del 01 de abril del 2008; también Página12, del 24 de junio del 2008.

67 Ver Página12, del 11 de junio del 2005, del 19 de febrero del 2006, del 20 de febrero del 2006, y del 13 de febrero del 2008.

68 Ver Página12, del 03 de octubre del 2007.

69 Ver ITN, del 15 de octubre del 2007 y del 01 de abril del 2008; también ver UNCTAD. (2008b). Pág. 9.

70 Ver ITN, de marzo del 2009.

71 En diversas ocasiones Argentina ha denunciado la falta de imparcialidad e independencia de los árbitros, pidiendo a menudo la remoción de alguno de los miembros de un panel, hasta ahora sin éxito; ver ITN, del 31 de julio del 2007.

72 Ver ITN, del 27 de mayo del 2007.

73 Vivendi también ha logrado que se condene a Argentina por no haberle proporcionado protección y plena seguridad, aplicando la lectura más amplía de esta cláusula. Curiosamente el argumento se apoya en un laudo precedente emitido por un panel en el que participaba como árbitro su abogado en esta causa. Ver ITN, del 30 de agosto del 2007. 
de expropiación indirecta, aunque éste se ha solicitado en todos los casos. Sin embargo, eso no ha sido ningún obstáculo para condenar a Argentina, ya que todos los paneles han realizado una interpretación extensiva de la cláusula de trato justo y equitativo, en la que parece caber todo.

Ahora bien, si Argentina ha llegado a este punto en el que intenta, de momento con poco éxito, hacer valer su soberanía nacional en casos de emergencia a través de una cláusula de sus TBI, es porque hace años abandonó la doctrina Calvo, abriendo la puerta al arbitraje internacional inversor-estado. Esa doctrina se basa precisamente en los principios de soberanía nacional, igualdad entre nacionales y extranjeros, y jurisdicción territorial, exigiendo agotar todos los recursos legales ante los tribunales locales ${ }^{74}$. De hecho, entre 1990 y 2000 Argentina suscribió $54 \mathrm{TBI}^{75}$ que, junto a cambios en la legislación interna que incluyen la reforma constitucional de 1994, estaban destinados a atraer inversión extranjera, en gran medida relacionada con el proceso de privatización ${ }^{76}$. Ello dio lugar a lo que se ha venido a llamar la "internacionalización del orden jurídico argentino"77, algunas de cuyas consecuencias se acaban de relatar. $Y$ a la vista del lastre que la suscripción de acuerdos sobre inversiones con arbitraje inversor-estado puede suponer para el desarrollo de un país, resulta necesario realizar una seria reconsideración del camino emprendido.

\section{ALTERNATIVAS}

Ante la necesidad de eludir los efectos negativos de un entramado jurídico tan perjudicial para llevar a cabo políticas de desarrollo, como el organizado por los acuerdos sobre inversiones con arbitraje inversor-estado, se impone la recuperación de la doctrina Calvo.

Aparente resultado de negociaciones internacionales, en realidad los AII son fruto de la imposición de las potencias económicas, dada la desigualdad de las partes, y suponen un avance en la "constitucionalización del ideal del fundamentalismo neoliberal de separar la actividad económica y la operación del mercado de toda exigencia e incidencia desde el ámbito de la democracia"78. En esa labor, las demandas inversor-estado, la puesta en pie de igualdad de empresas y estados ante paneles de expertos regidos por el derecho mercantil internacional, suponen un salto cualitativo en la profundización de una estrategia nefasta que nos aleja del desarrollo humano.

Por eso, hay que eliminar esa prerrogativa inaceptable, avanzando hacia el control democrático de las actividades de las empresas multinacionales sobre la base de la primacía absoluta de los derechos humanos, incluido el derecho al desarrollo frente al beneficio empresarial. Claro que para ello hay que poner los medios que pueden inspirarse en las siguientes propuestas ${ }^{79}$ : en primer lugar, dar a conocer excesos tan clamorosos como la institucionalización de las demandas inversor-estado a través de unos acuerdos internacionales de inversión que nunca debieron suscribirse, y promover su denuncia que está en manos de cada uno de los gobiernos firmantes. En segundo lugar, impulsar el ejercicio efectivo del control de constitucionalidad de los AII, ya que pueden ser declarados inaplicables si violan las garantías fundamentales de la constitución o los derechos humanos. En tercer lugar, recuperar la doctrina Calvo, lo que es tanto como revertir la tendencia y acabar con los privilegios de los inversores extranjeros.

En efecto, la doctrina Calvo surgió en el siglo XIX en Latinoamérica como respuesta al expansionismo imperialista de las potencias europeas, rechazando el uso de la "protección diplomática" de sus nacionales y otras formas de intervención $\operatorname{armada}^{80}$. La doctrina Drago la reforzó al comenzar el siglo XX, al rechazar el empleo de la fuerza

74 Ver Teitelbaum. (2004). Pág. 16; (2007). Pág. 154.

75 Ver Stanley. (2004). Págs. 22 y 61-62.

76 Conviene recordar que la estrategia neoliberal puesta en marcha por el presidente Menem en 1989, basada en la apertura al exterior, la desregulación y la privatización, y anclada en una dolarización de hecho (régimen de convertibilidad), hizo que Argentina fuera considerada una "alumna ejemplar" por el FMI, el Banco Mundial y otras instituciones internacionales. Entonces era un modelo de mercado emergente.

77 Ver Granato. (2005). Pág. 93.

78 Ver Lander, citado por Teitelbaum. (2004). Pág. 2.

79 Las tres propuestas realizadas se basan en Teitelbaum. (2004). Págs. 12-20 y Teitelbaum. (2007). Págs. 153-159, donde pueden encontrarse algunas más, también destinadas a "salir del atolladero y reconquistar la autodeterminación".

80 "En el Derecho Internacional, desde el punto de vista estrictamente jurídico, el cobro de los créditos y las reclamaciones privadas no justifican de plano la intervención armada de los gobiernos, y como los Estados europeos siguen entre ellos 
o la ocupación como forma de cobrar deudas de un estado, que posteriormente se extendió también a los casos de obligaciones contractuales. La doctrina dio lugar a la cláusula Calvo, que en los convenios donde figura establece que los posibles conflictos deben resolverse en los tribunales locales, quedando vedado el recurso al arbitraje internacional ${ }^{81}$.

La doctrina Calvo ha gozado de gran predicamento en el ámbito latinoamericano hasta los años 90 y está recogida en varias constituciones de países del área. Fue esgrimida en 1938 por México frente a Estados Unidos, que reclamaba que las expropiaciones de petróleo se remitieran a un arbitraje vinculante y a una indemnización "rápida, adecuada y efectiva". A pesar de la decidida oposición de Estados Unidos, esta doctrina quedó consagrada en la Carta de la Organización de Estados Americanos (OEA) de 1948, y fue reafirmada por la OEA en 1975 mediante una declaración ${ }^{82}$ que contradice claramente todo lo que luego está pasando con los AII. Y conviene subrayar que, bajo el principio de soberanía nacional y jurisdicción territorial, se postula que los extranjeros tienen los mismos derechos que los nacionales, pero no más, como ocurre con los AII.

Y aunque los tiempos han cambiado, es hora de recuperar la doctrina Calvo; esto es, la soberanía jurisdiccional frente a las multinacionales, porque estas van a seguir practicando el cabildeo activamente para que sus países de origen sigan firmando All de nueva generación, que incluyan todas esas cosas que más arriba se han señalado como excesos, y algunas más. Así lo expresa con todo lujo de detalles el documento que presentaba la estrategia de la patronal europea sobre los acuerdos de libre comercio de la Unión Europea ${ }^{83}$. El sentido de la marcha ya está marcado, y los actuales gobiernos de Bolivia y Ecuador han dado los primeros pasos, así que hay que continuar decididamente por ese camino, que pasa necesaria- mente por recuperar cotas de soberanía nacional para desarrollar políticas de desarrollo pero sin olvidar que, en general, se avanza más y mejor en grupo que en solitario, por lo que actuaciones colectivas de un conjunto significativo de países latinoamericanos pueden resultar menos gravosas y más eficaces que gestos individuales.

\section{BIBLIOGRAFÍA}

Burke-White, William W. y Von Staden, Andreas. (2008). "Investment Protection in Extraordinary Times: The Interpretation and Application of Non-Precluded Measures Provisions in Bilateral Investment Treaties". En:Journal of International Law. Vol. 48, № 2. Virginia, Universidad de Virginia.

Elkins, Zachary; Guzmán, Andrew T. y Simmons, Beth. (2008). "Competing for Capital: the Difussion of Bilateral Investment Treaties, 1960-2000”. En: University of Illinois Law Review. Vol 2008, № 1. Illinois, University of Illinois.

Franck, Susan D. (2007). "Empirically Evaluating Claims about Investment Treaty Arbitration”. En: North Carolina Law Review Vol 86. North Carolina, Universidad de Carolina del Norte.

Gobierno de Bolivia, Equipo de Análisis del Ministerio de Asuntos Exteriores y Cultos. (2008). Bolivia y el CIADI: crónica de un divorcio anunciado. En: Valdomir y Santos. (2008).

Miguel, María Haydée. (2005). "Caso Cartellone: ¿es también una cálida manta para Calvo?". En: Revista Jurídica de la Federación Interamericana de Abogados. Vol. 3.

Sacerdoti, Giorgio. (2007). The proliferation of BITs: Conflicto of Treaties, Proceedings and Awards. Bocconi University, Institute of Comparative Law (IDC). Research Paper № 07-02.

invariablemente la regla de no intervención por problemas económicos, no hay ningún motivo para que no la impongan también en sus relaciones con las naciones del nuevo mundo". Ver Carlos Calvo, citado por Miguel. (2005). Pág. 2.

81 Ver Miguel. (2005). Pág. 2.

82 La Declaración del Consejo Permanente de la OEA de julio de 1975 dice: "Las empresas transnacionales deben someterse a la legislación y jurisdicción de los tribunales nacionales competentes de los países donde realizan sus actividades y ajustarse a la política de desarrollo de los mismos". Ver Miguel. (2005). Pág. 2. La doctrina Calvo también ha sido apoyada por numerosos países del resto del mundo, particularmente ex colonias. Así, inspiró la Resolución de la Asamblea General de la ONU de 17 de diciembre de 1973 que proclama la soberanía permanente de los estados sobre los recursos naturales, y un año más tarde la Carta de los Derechos y Deberes Económicos de los Estados. Ver Public Citizen. (2005). Págs. 35-36; y Teitelbaum (2004). Págs. 16-18.

83 Ver UNICE. (2006). 
Teitelbaum, Alejandro. (2007). Al Margen de la Ley. Sociedades Transnacionales y Derechos Humanos. Bogotá, Instituto Latinoamericano de Servicios Legales Alternativos (ILSA).

\section{INTERNET}

CIADI. List of Cases. Consultada el 14 de octubre del 2009. Disponible en: www.worldbank. org/icsid

Cosbey, Aaron; Mann, H.; Peterson, L.E. y Von Moltke, K. (2004). “Inversiones y desarrollo sustentable. Una guía referente a la utilización actual y al futuro potencial de los acuerdos internacionales sobre inversiones". International Institute for Sustanaible Development (IISD). Disponible en: $w w w$. iisd.org.

Gal-Or, Noemi. (2005). "NAFTA Chapter Eleven and the implications for the FTAA: the institutionalization of investor status in public international law". En: Transnational Corporations, Vol. 14, № 2, agosto. Disponible en: www.unctad.org.

Granato, Leonardo. (2005). Protección del inversor extranjero y arbitraje internacional en los Tratados Bilaterales de Inversión. Universidad de Belgrano, Argentina. Disponible en: $w w w$. eumed.net/libros/2005/lg/index.htm.

Gutiérrez-Haces, Teresa. (2008). "Acerca de la protección a la inversión extranjera”. En: $A L A I$, América Latina en Movimiento, noviembre. Disponible en: http://alainet.org.

INTERMÓN. (2008). Letra pequeña, grandes abusos. Por qué los contratos petroleros en América Latina son un obstáculo para el desarrollo. Informe de Intermón Oxfam № 12, julio. Disponible en: www.intermonoxfam.org.

ITN. Investment Treaty News. Disponible en: $w w w$. investmenttreatynews.org.

Lowe, Vaughan. (2007). "Changing Dimensions of International Investment Law”. En: University of Oxford Faculty of Law Legal Studies Research Paper Series № 4/2007. Disponible en: http://papers.ssrn.com/Abstract $=970727$.

Malik, Mahnaz. (2008). "Recent Developments in International Investment Agreements and the Right of States to Regulate: 2007-2008”. En: 2nd Annual Forum of Developing Country Investment Negotiators. Marrakech, 03-04 de noviembre. Disponible en: www.iisd.org.

Mann, Howard. (2008). International Investment Agreements, Business and Human Rights: Key Issues and Opportunities. International Institute for Sustanaible Development (IISD). Disponible en: www.iisd.org.

Marshall, Fiona. (2008). "Advances in InvestorState Arbitration”. En: 2nd Annual Forum of Developing Country Investment Negotiators. Marrakech, 03-04 de noviembre. Disponible en: www.ïsd.org.

Mortimore, Michael y Stanley, Leonardo. (2006). "Obsolescencia de la protección a los inversores extranjeros después de la crisis argentina”. En: Revista de la CEPAL № 88, abril. Disponible en: www.eclac.org/revista.

Public Citizen. (2005). Capítulo 11 del TLCAN y los Litigios de Inversionistas contra Estados. Lecciones para el Tratado de Libre Comercio de Centroamérica. Public Citizen's Global Trade Watch. Disponible en: www.citizen.org.

Sondow, Michael. (2006). "Privatizando la justicia: el arbitraje en los tratados comerciales internacionales”. En: Rebelión, 06 de septiembre. Disponible en: $w w w$.rebelion.org.

Stanley, Leonardo. (2004). "Acuerdos bilaterales de inversión y demandas ante Tribunales Internacionales: la experiencia argentina reciente". En: CEPAL, Serie desarrollo productivo № 158, octubre. Disponible en: $w w w$. eclac.org.

Teitelbaum, Alejandro. (2004). "El ALCA entre nosotros: los tratados bilaterales de libre comercio". Ponencia en III Congreso Internacional Derechos y Garantías en el siglo $X X I$. Facultad de Derecho de la Universidad Nacional de Buenos Aires, 08 al 10 de septiembre. Disponible en: www.bilaterals.org.

UNCTAD (2006a): International Investment Arrangements: Trends and Emerging Issues. UNCTAD Series on International Investment Policies for Development. Disponible en: $w w w$. unctad.org.

UNCTAD. (2004). Key Terms and Concepts in IIAs: A Glossary. UNCTAD Series on Issues in International Investment Agreements. Disponible en: www.unctad.org.

UNCTAD. (2005). Investor-State Disputes Arising from Investment Treaties: A Review. UNCTAD 
Series on International Investment Policies for Development. Disponible en: $w w w$. unctad.org.

UNCTAD. (2006b). "Latest Developments in Investor-State Dispute Settlement”. En: IIA Monitor № 4. Disponible en: www.unctad. org.

UNCTAD. (2008a). World Investment Report: Transnational Corporations, and the Infrastructure Challenge. Disponible en: www.unctad.org.

UNCTAD. (2008b). "Latest developments in investor-State dispute Settlement". En: IIA Monitor № 1 . Disponible en: www.unctad.org.

UNCTAD. (2008c). "Recent developments in international investment agreements (2007-June 2008)”. En: IIA MONITOR № 2. Disponible en: www.unctad.org.

UNCTAD. Base de datos sobre Acuerdos Internacionales sobre Inversiones: www.unctad.org/ iia consultada el 01 de octubre del 2009.
UNICE. (2006). UNICE Strategy on an EU Approach to Free Trade Agreements. Bruselas, 07 de diciembre. Disponible en: www.unice.org.

Valdomir, Sebastián y Santos, Carlos (eds.) (2008). Soberanía de los pueblos o intereses empresariales. Los mecanismos de arreglos de diferencias Inversor-Estado y sus impactos sobre los derechos humanos y el ambiente. REDES-Amigos de la Tierra Uruguay y Fundación Solón de Bolivia. Disponible en: www.redes.org.uy.

Von Moltke, Konrad y Mann, Howard. (2004). Towards a Southern Agenda on International Investment: Discussion Paper on the Role of International Investment Agreements. International Institute for Sustanaible Development (IISD). Disponible en: www.iisd.org.

Yu, Vicente y Marshall, Fiona. (2008). "Investors' Obligations and Host State Policy Space”. En: 2nd Annual Forum of Developing Country Investment Negotiators. Marrakech, 03-04 de noviembre. Disponible en: www.iisd.org. 